\title{
Analysis of Volatile Compounds from the Concrete of Jasminum multiflorum Flowers
}

\author{
P. Ranchana*, M. Ganga, M. Jawaharlal and M. Kannan \\ Department of Floriculture and Landscaping, HC\& RI, TNAU, Coimbatore, Tamil Nadu, India \\ *Corresponding author
}

\begin{tabular}{|l|}
\hline K e y w o r d s \\
Jasmine, Jasminum \\
multiflorum, Concrete, \\
Volatile compounds, \\
GC-MS.
\end{tabular}

A B S T R A C T
Essential oils are plant-based volatile oils with strong aromatic components that are made up of different chemical compounds like alcohols, hydrocarbons, phenols, aldehydes, esters and ketones (Younis et al., 2008). Jasmine essential oil possesses sweet floral aroma and has powerful characteristics that aid the body as an anti-depressant and aphrodisiac. Three species of jasmine viz., Jasminum sambac, Jasminum auriculatum and Jasminum grandiflorum have attained commercial significance (Rimando, 2003; Green and Miller, 2009). But Jasminum multiflorum is cultivated commercially to some extent in Karnataka. The flowers of Jasminum multiflorum genotypes viz., local variety (Kakada) and a clone Acc.JM.1 was used in this experiment. In this study, Jasminum multiflorum concrete extraction was carried out by solvent extraction with hexane. The chemical composition of the concrete was analysed by gas chromatography- mass spectrometry (GC-MS). The major chemical components detected were Triacontane; Tetratriacontane; 1-Pentanol, 4methyl-2-propyl and Nonacosane. The result of this study showed that the GC-MS study is selective, rapid and efficient for the identification of volatile components and composition variations.

\section{Introduction}

Jasmine is a highly valued ornamental plant for home gardens and commercial cultivation. Flowers and buds are used for making garlands, bouquets and for religious offerings, while 'veni' is used as hair adornment. The flowers are also used for the production of perfumed hair oils and attars. Three species of jasmine (Jasminum sambac, Jasminum auriculatum and Jasminum grandiflorum) have attained commercial significance (Rimando, 2003; Green and Miller, 2009). Jasminum multiflorum (Syn: Jasminum pubescens) is commercially cultivated to some extent in Karnataka but not in Tamil Nadu. Local variety (Kakada) exhibits the characters of complete white flowers in clusters, very ornamental and flowers profusely for a long duration. It is commonly called as Furry jasmine, Downy jasmine, Star jasmine, Pinwheel jasmine. Tamil Nadu Agricultural University, Coimbatore has identified a new clone in Jasminum multiflorum as Acc.JM.1. The flowers are sessile, large, fragrant, light pink colour bud, pure white open flower and borne in terminal umbels; petals six to nine, lanceolate and exhibited year-round flowering potential

The fully blossomed flower is used to extract its oil and concrete. A non-polar solvent such 
as Hexane is used to extract the aromatic compounds from the flowers. At the end of the process, the hexane is evaporated leaving behind a waxy, semisolid substance known as concrete. Presence of all volatile compounds in the flowers only will give good quality concrete. In nature all the volatile compounds are fixed in the flowers with fibrous materials. Gas Chromatography-Mass Spectrometry (GCMS) is a process that integrated the features of gas chromatography and mass spectrometry to improve efficacy of qualitative and quantitative analysis within a test sample. The gas chromatograph applies which depend on the column (type, material, length, diameter, film thickness) as well as the phase properties. The mass spectrometer does this by breaking each molecule into ionized fragments and detecting these fragments using their mass to charge ratio (Bramer, 1998). Applications of GC-MS include drug detection, plasma detection, environmental analysis, explosives investigation, and identification of unknown samples. Additionally, it can identify trace elements in materials that were previously thought to have disintegrated beyond identification. The purpose of this study was to identify the volatile compounds released from Jasminum multiflorum genotypes local variety and clone Acc.JM.1.

\section{Materials and Methods}

\section{Flower preparations}

Freshly opened blossoms were collected every day before 9.30 a.m., weighed and subjected to extraction.

\section{Extraction method- solvent extraction}

For extraction of concrete, the flowers were harvested when fully opened before 9.30 AM. Concrete content of flowers was analyzed by solvent extraction method (ASTA, 1960) with food grade hexane, averaged and expressed in per cent of concrete recovery. A sample of fifty gram was taken in the glass column of Soxhlet apparatus and concrete content was estimated using food grade hexane as solvent. Soluble extract was then drained off into a pre weighed $100 \mathrm{ml}$ beaker $\left(\mathrm{W}_{1}\right)$. The extract was then evaporated on a steam bath and heated for 30 minutes in an oven at $60^{\circ} \mathrm{C}$, cooled and weighed $\left(\mathrm{W}_{2}\right)$. The concrete content was calculated using the following formula and expressed in per cent.

Concrete content $(\%)=\frac{\mathrm{W}_{2}-\mathrm{W}_{1}}{\text {---------- }}$ x 100

\section{Volatile compound analysis using GC/MS analysis}

The volatile oil from Jasminum multiflorum genotypes (local variety and clone Acc.JM.1) flowers was dissolved in hexane and directly injected into the injection port of gas chromatograph (Agilent Technologies 7890A GC system) coupled with a mass spectrometer (Agilent Technologies 5975C inert XL EI/CI MSD with Triple-Axis Detector). The GC was operated on an Agilent J\&W GC column HP5 column (30 m x $0.32 \mathrm{~mm}$, id. with $0.52 \mu \mathrm{m}$ film thickness) and helium was used as the carrier gas. The temperature program was started with an initial temperature of $150^{\circ} \mathrm{C}$ and held for $4 \mathrm{~min}$ at this temperature, then heated up to $170^{\circ} \mathrm{C}$ with a heating rate of $0.8^{\circ} \mathrm{C} / \mathrm{min}$ and held for $1 \mathrm{~min}$, heated up to $220^{\circ} \mathrm{C}$ with a heating rate of $3.0^{\circ} \mathrm{C} / \mathrm{min}$ and held for $1 \mathrm{~min}$, heated up to $240^{\circ} \mathrm{C}$ with a heating rate of $1.0^{\circ} \mathrm{C} / \mathrm{min}$ and held for $1 \mathrm{~min}$ and heated up to $250^{\circ} \mathrm{C}$ with a heating rate of $5.0^{\circ} \mathrm{C} / \mathrm{min}$ and held for $5 \mathrm{~min}$ at a flow rate of $0.7 \mathrm{~mL} / \mathrm{min}$. The obtained mass spectra were preliminarily interpreted by comparing with those of Enhance Chemstation Version D00.00.38 (Agilent Technologies), the Mass Spectral Search Library of the National Institute of Standards and Technology (NIST, Gaithersburg, USA). 


\section{Results and Discussion}

The concrete of Jasminum multiflorum local variety and clone Acc.JM.1 was prepared by solvent extraction and it constitutes $0.33 \%$ and $0.31 \%$ per cent. The chromatogram generated by gas chromatography showed that the composition of the volatile oils from Jasminum multiflorum genotypes viz., Local variety (white flower bud) and Acc.JM.1 clone (Fig. 1).
GC/MS analysis of Local variety of Jasminum multiflorum concrete opined that Triacontane; Tetratriacontane; Tetracosane; Nonacosane and Octacosane were identified as major compounds. Whereas, 13-Heptadecyn-1-ol; Z(13, 14-Epoxy) tetradec-11-en-1-ol acetate; Z, Z-3, 15-Octadecadien-1-ol acetate; Ethanol, 2(9-octadecenyloxy)-, (Z)- and 12-Methyl-E, E2,13-octadecadien-1-ol were present as trace elements (Table 1, Fig. 2).

Fig.1 The GC chromatograms of volatile compounds of Jasminum multiflorum genotypes (Local variety and Acc.JM.1 clone)
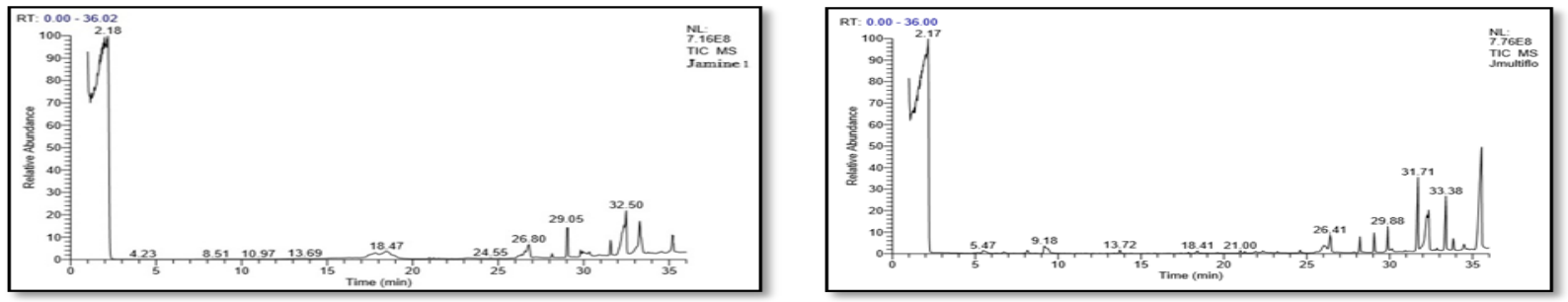

Fig.2 Chemical structure of volatile compounds of local variety of Jasminum multiflorum

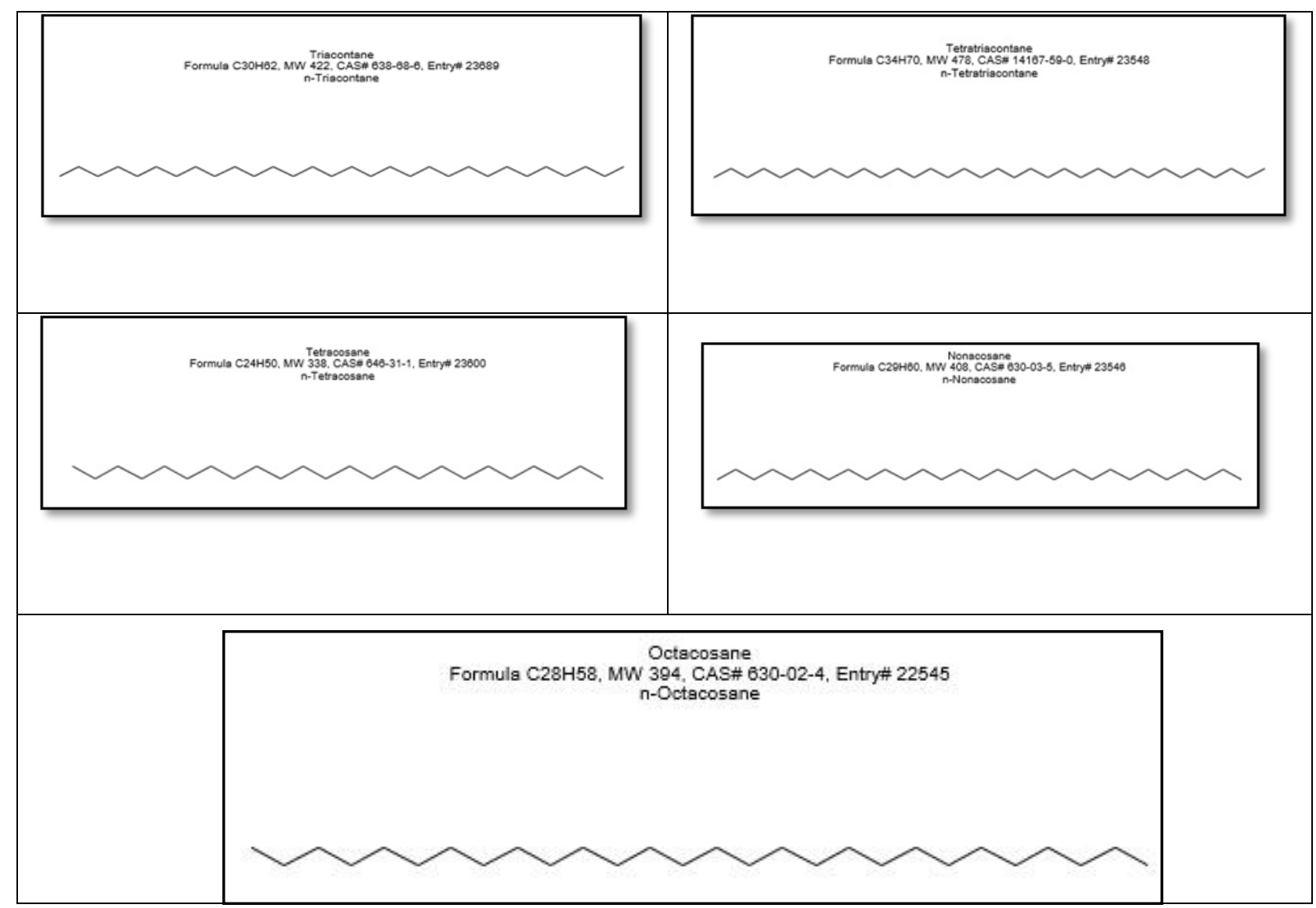


Fig.3 Chemical structure of volatile compounds of Jasminum multiflorum clone Acc.JM.1

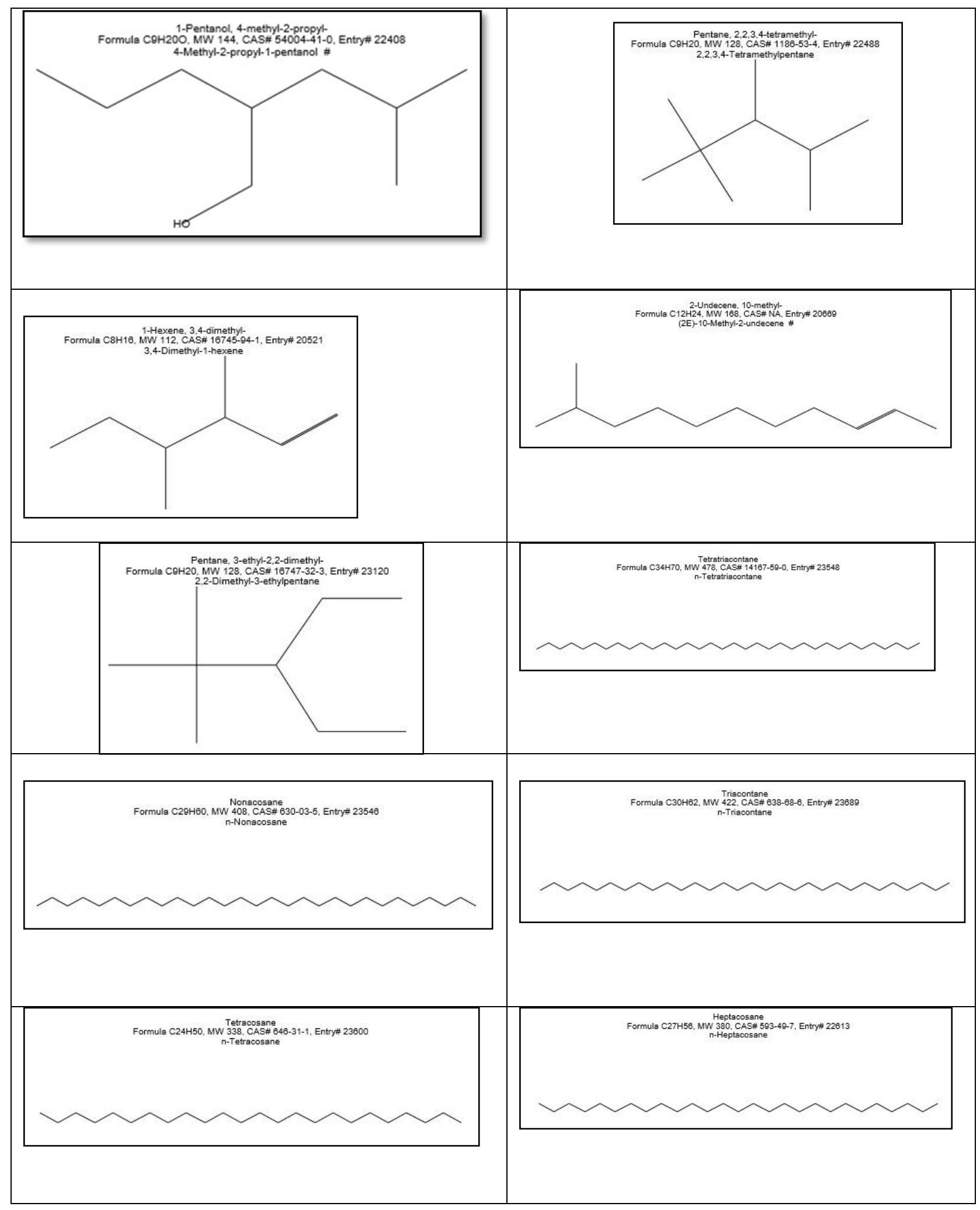


Table.1 Chemical composition of J. multiflorum local variety concrete

\begin{tabular}{|l|c|l|c|c|}
\hline S.No & RT & Compounds available & Molecular weight & \% Retention area \\
\hline 1. & 2.14 & Triacontane & 422 & 69.66 \\
\hline 2. & 2.14 & Tetratriacontane & 478 & 69.66 \\
\hline 3. & 2.14 & Tetracosane & 338 & 69.66 \\
\hline 4. & 2.14 & Nonacosane & 408 & 69.66 \\
\hline 5. & 2.14 & Octacosane & 394 & 69.66 \\
\hline
\end{tabular}

Table.2 Chemical composition of J. multiflorum clone Acc.JM.1 concrete

\begin{tabular}{|l|l|l|c|c|}
\hline S.No & RT & \multicolumn{1}{|c|}{ Compounds available } & Molecular weight & \% Retention area \\
\hline 1. & 2.07 & 1-Pentanol,4-methyl-2-propyl- & 144 & 61.42 \\
\hline 2. & 2.07 & Pentane,2,2,3,4-tetramethyl- & 128 & 61.42 \\
\hline 3. & 2.07 & 1-Hexene,3,4-dimethyl- & 112 & 61.42 \\
\hline 4. & 2.07 & 2-Undecene,10-methyl- & 168 & 61.42 \\
\hline 5. & 2.07 & Pentane,3-ethyl-2,2-dimethyl- & 128 & 61.42 \\
\hline 6. & 35.49 & Tetratriacontane & 478 & 12.06 \\
\hline 7. & 35.49 & Nonacosane & 408 & 12.06 \\
\hline 8. & 35.49 & Triacontane & 422 & 12.06 \\
\hline 9. & 35.49 & Tetracosane & 338 & 12.06 \\
\hline 10. & 35.49 & Heptacosane & 380 & 12.06 \\
\hline
\end{tabular}

GC/MS analysis of Jasminum multiflorum clone Acc.JM.1 concrete resulted in the identification of major compounds as 1-Pentanol,4-methyl-2propyl-; Pentane,2,2,3,4-tetramethyl-; 1Hexene,3,4-dimethyl-; 2-Undecene,10-methyl-; Pentane,3-ethyl-2,2-dimethyl-;

Tetratriacontane; Nonacosane; Triacontane; Tetracosane and Heptacosane were (Table 2, Fig. 3). Whereas, 2,5-Octadecadiynoic acid, methyl ester; cis-5,8,11,14,17-Eicosapentaenoic acid; 10-Chlorotricyclo [4.2.1.1(2,5)] deca-3,7dien-9-ol; Methyl 10,12-pentacosadiynoate and 1,5: 2,4-Dimethanopentalene-3,6-diol, octa hydro- were present as minor compounds.

\section{References}

ASTA 1960. Official analytical methods of the American Spice Trade Association, New York, pp. 41-42.
Bramer S. E. V.1998. An Introduction to Mass Spectrometry. Widener University. Department of Chemistry. pp.26.

Green, P. and Miller, D. 2009. The genus Jasminum in cultivation. Kew Publishing, Royal Botanic Gardens, Kew.

Rimando, T. J. 2003. Sampaguita production. In: Ornamental Horticulture: A little giant in the tropics. SEAMEO SEARCA and UPLB, College, Los Banos, Laguna, Philippines, pp: 333.

Younis, A., Riaz, A., Khan, M. A., Khan, A. A. and Pervez, M. A. 2008. Extraction and identification of chemical constituents of the essential oil of Rosa species. Acta Hort., 766: 485-492.

\section{How to cite this article:}

Ranchana, P., M. Ganga, M. Jawaharlal and Kannan, M. 2017. Analysis of Volatile Compounds from the Concrete of Jasminum multiflorum Flowers. Int.J.Curr.Microbiol.App.Sci. 6(11): 2229-2233. doi: https://doi.org/10.20546/ijcmas.2017.611.264 